\title{
Investigation of drop geometry at free-falling process depending on volume of dozing
}

\author{
Ksenia A. Batischeva ${ }^{a}$, Evgenija G. Orlova and Dmitriy V. Feoktistov \\ Department of Theoretical and Industrial Heat Systems Engineering, Institute of Power Engineering, \\ Tomsk Polytechnic University, 634050 Tomsk, Russia
}

\begin{abstract}
Present work performs experimental investigation of the changes in the geometric shape of the drop in terms of its free-falling, depending on the conditions of drop formation on dispenser. It was found that volume and velocity of drop formation on dispenser are the factors affecting the geometric shape of the drop in terms of its free-falling.
\end{abstract}

\section{Introduction}

Deformation of drops on a solid surface has been studied by the authors [1-3], but studies with using high-speed cameras have been made relatively recently [4]. Nowadays there are no models allowing to make prognostic assessment of changes in drop shape in terms of its free-falling, depending on the conditions of drop formation on dispenser. Progress in this area of science is constrained by the lack of comprehensive experimental studies using high-speed cameras.

The purpose of the work is conducting a series of experiments for study of the changes in the geometric shape of the drop when its free-falling, depending on the conditions of drop formation on dispenser.

\section{Research technique}

A scheme of experimental setup is shown in Fig. 1.

The main elements of experimental setup are light source 1 , substrate 2, high-speed camera 5 and dispenser 8 for drop formation.

The transparent box 4 made of glass is destined for reducing of the impact of environmental factors, such as a movement of air mass, differential temperature in the room. The opening from top is needed for unhindered drops free-falling, side openings are needed for path of parallel rays from the light source 1 to the camera lens 5 .

As test substrate we use flexible copper disk (Fig. 2) of thickness $4 \mathrm{~mm}$ and diameter $54 \mathrm{~mm}$.

The rate of water supply through pipe 7 to dispenser 8 is controlled by electronic unit pump 6 (Cole-Parmer Touch Screen). This pump is shown in Fig. 3.

Shadow method was used to record drop spreading process [5-7].

\footnotetext{
${ }^{a}$ Corresponding author: bka1801@mail.ru
}

This is an Open Access article distributed under the terms of the Creative Commons Attribution License 4.0, which permits unrestricted use, distribution, and reproduction in any medium, provided the original work is properly cited. 


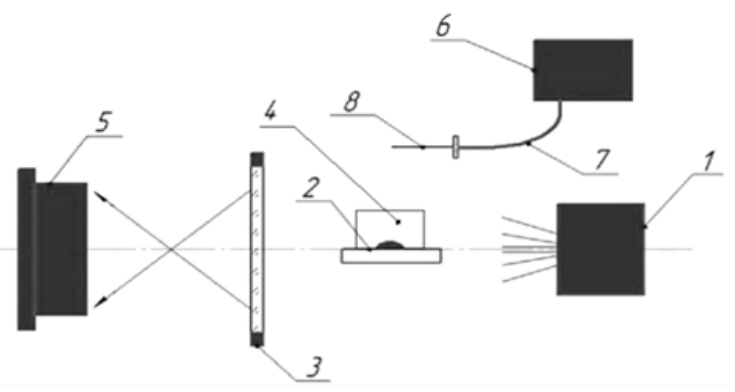

Figure 1. A scheme of experimental setup:1 - light source; 2 - substrate; 3 - condensing lens; 4 - transparent box; 5 - high-speed camera; 6 - electronic unit pump; 7 - pipe of experimental liquid supply; 8 - dispenser for drop formation.

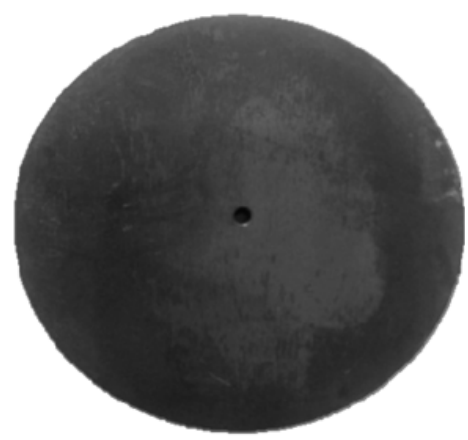

Figure 2. Flexible copper disk.

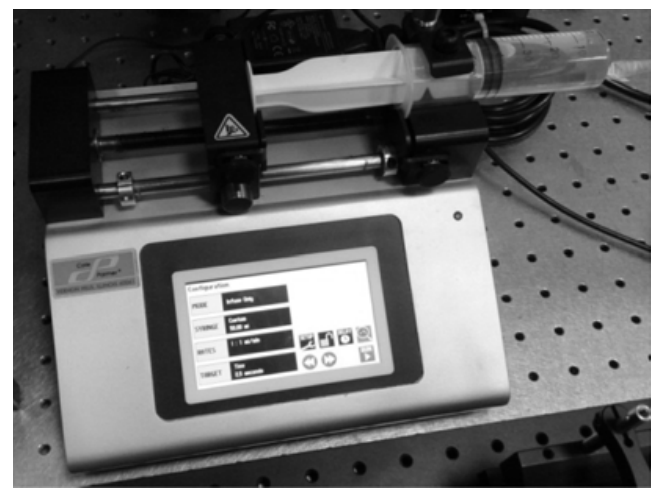

Figure 3. Electronic unit pump Cole-Parmer Touch Screen.

\section{Results and discussions}

Drops have been dosed to the surface from a height of 50-300 $\mathrm{mm}$ with step of height change of $50 \mathrm{~mm}$.

The dosing devices are the needles with different inside diameters for formation of drops with volumes: $0.006 \mathrm{ml} ; 0.012 \mathrm{ml}$; $0.018 \mathrm{ml} ; 0.023 \mathrm{ml} ; 0.048 \mathrm{ml}$ (Fig. 4). 
Thermophysical Basis of Energy Technologies
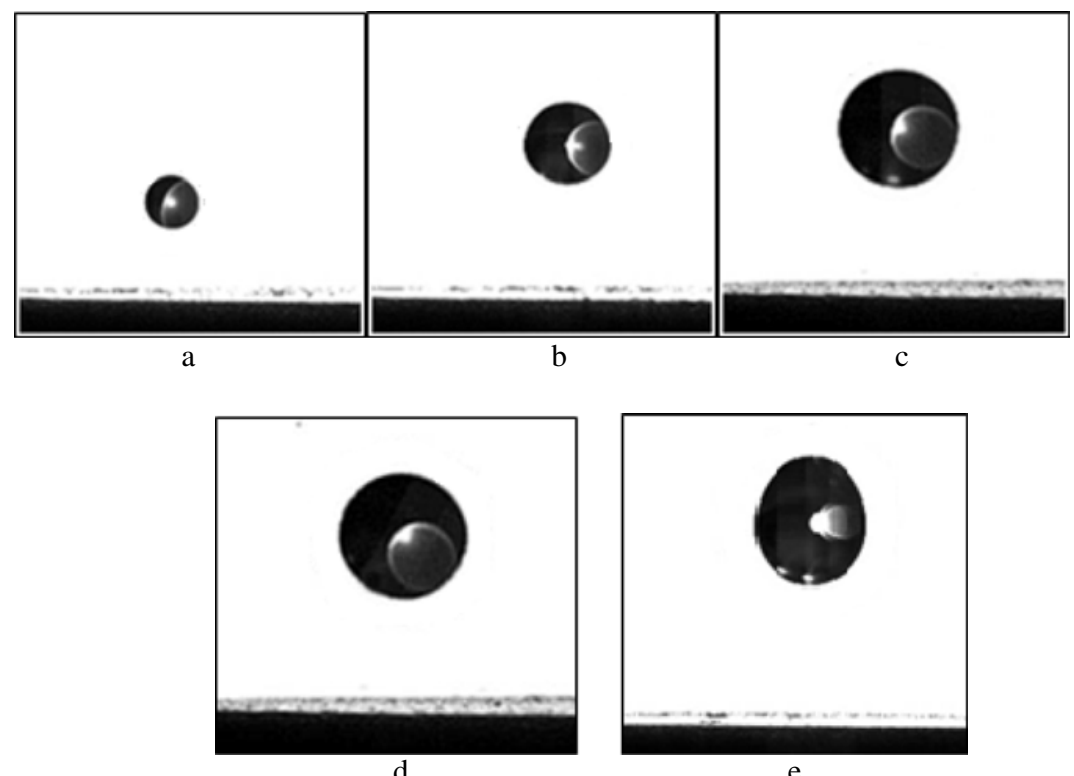

e

Figure 4. Drop free-falling with volumes: a) V $=0.006 \mathrm{ml}$; b) $\mathrm{V}=0.012 \mathrm{ml}$; c) $\mathrm{V}=0.018 \mathrm{ml}$; d) $\mathrm{V}=0.023 \mathrm{ml}$; e) $\mathrm{V}=0.048 \mathrm{ml}$.
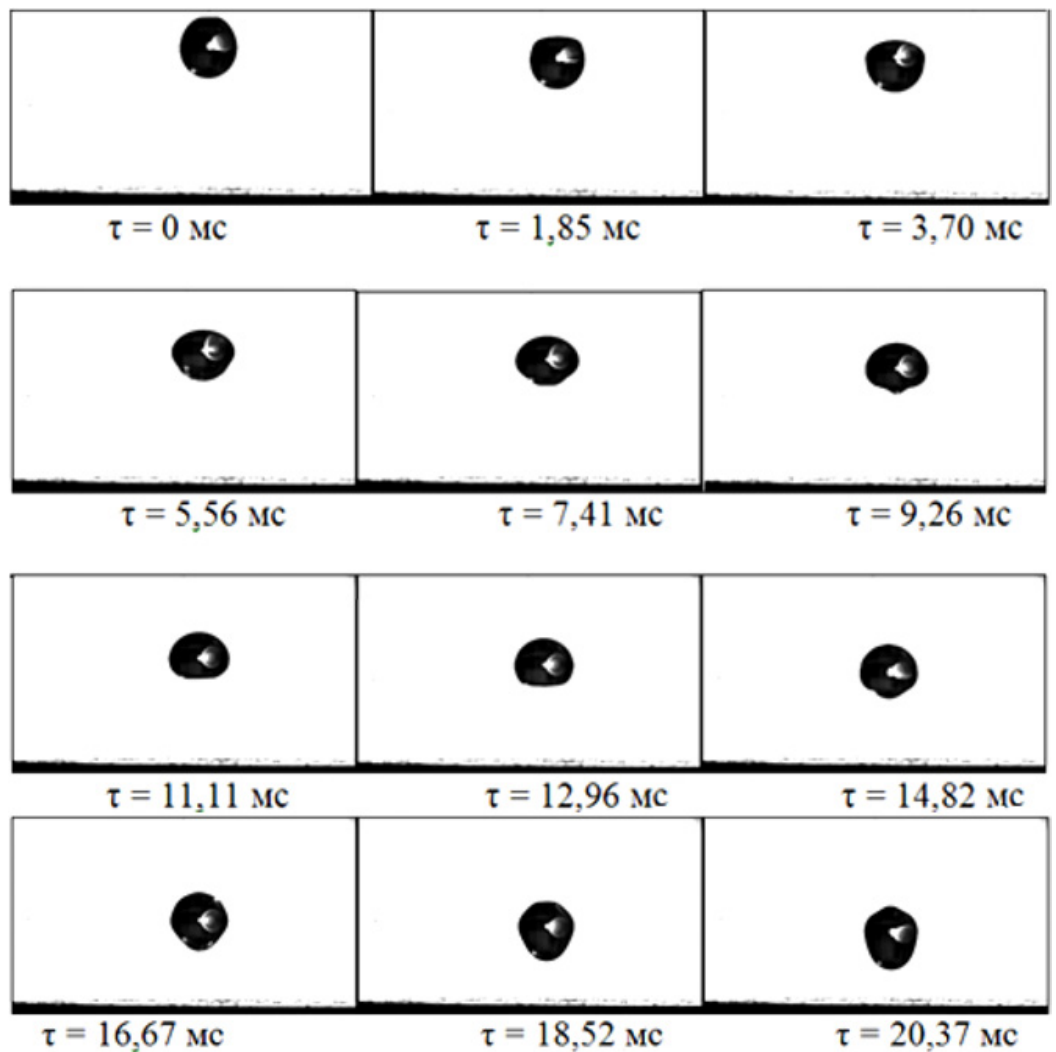

Figure 5. Snapshots of the falling drops process with volume $\mathrm{V}=0,048 \mathrm{ml}$. 
Table 1. Geometric characteristics of drops at different volume of dosing.

\begin{tabular}{|l|l|l|l|l|l|}
\hline Volume of drop dosing, ml & 0.006 & 0.012 & 0.018 & 0.023 & 0.048 \\
\hline Drop diameter at free-falling, mm & 2.24 & 2.88 & 3.25 & 3.55 & 4.5 \\
\hline Drop mass, mg & 5.84 & 12.44 & 17.97 & 23.41 & 47.69 \\
\hline $\begin{array}{l}\text { Drop velocity when approaching substrate from } \\
\text { height of 300 mm, m/sec }\end{array}$ & 2.45 & 2.45 & 2.45 & 2.45 & 2.45 \\
\hline
\end{tabular}

It was found that drop volume is the factor affecting the geometrical shape of drop in terms of its free-falling. Drops with volume up to $0.023 \mathrm{ml}$ don't change spheroidal shape at free-falling. Drop with volume $0.048 \mathrm{ml}$ changes geometrical form at random (Fig. 5).

It was found that velocity of droplets extrusion with a syringe dispenser affects droplet shape in terms of its free-falling. It should be noted that drop with small sizes $(0.006 \mathrm{ml})$ at velocity of formation of greater than $0.1 \mathrm{ml} / \mathrm{sec}$ changes geometric shape while falling.

The main factor affecting geometrical shape of drop is the drop volume at low velocities of droplets extrusion with a syringe dispenser (up to $0.1 \mathrm{ml} / \mathrm{sec}$ ).

Geometric characteristics of the falling drops were fixed by indirect method (at video processing). The experimental data are summarized in Table 1.

It was found, that condition of drop formation on dispenser (in particular liquid flow rate) affects geometric form of drop in terms of its free-falling.

\section{References}

[1] S.A. Borodin, Computer optics. 28, 66 (2005)

[2] N.N. Avakimyan, N.I. Vasiliev, V.V. Guguchkin, IV Minsk International Forum on Heat and Mass Transfer. 10, 315 (2000)

[3] B.A. Uryukov, V.D. Belik, G.V. Tkachenko, J. Eng. Phys. Thermophys. 2, 299 (2012)

[4] D. Bartolo, C. Josserand, D. Bonn, Phys. Rev. E. 62, 756 (2006)

[5] V.Y. Gubarev, A.G. Arzamastcev, Thermal Processes in Engineering 2, 63 (2010)

[6] E. Orlova, G. Kuznetsov and D. Feoktistov, EPJ Web of Conferences 76, 012039 (2014)

[7] E. Ya. Gatapova, A.A. Semenov, D.V. Zaitsev, O.A. Kabov, Colloid Surface A 441, 776 (2014) 